\title{
Editorial: IMA Health 2010
}

\author{
Christos Vasilakis • Thierry Chaussalet • Rose Baker
}

Received: 28 June 2011 / Accepted: 29 June 2011 / Published online: 12 July 2011

(C) Springer Science+Business Media, LLC 2011

\section{Background}

Ten years into the new millennium, health and social care organisations and policymakers are faced with unprecedented demands to increase both the quantity and quality of service delivery [1]. In the wake of the 2008 financial crisis and resulting tight budgetary conditions across most developed countries, these improvements are expected to take place while simultaneously achieving substantial cost savings [2]. The problems are further exacerbated by the changes in demography and the ageing of the population as observed in particular in the developed countries [3]. At the same time and perhaps more alarmingly, improving health in low-income countries is still as big a challenge as it has ever been [4]. Within this context, health and social care systems are undergoing major changes worldwide.

Is there a role for mathematical modelling and computer simulation (statistical analysis, stochastic processes, queuing theory, mathematical programming, heuristics, discrete event simulation, system dynamics, etc.) in helping to solve these multifaceted problems? Over the years, extensive

C. Vasilakis $(\bowtie)$

UCL Clinical Operational Research Unit,

Department of Mathematics, University College London,

4 Taviton Street,

London WC1H 0BT, UK

e-mail: c.vasilakis@ucl.ac.uk

T. Chaussalet

Health and Social Care Modelling Group, School of Electronics and Computer Science, University of Westminster,

London, UK

R. Baker

Centre for OR and Applied Statistics, School of Business,

University of Salford,

Salford, UK research and development has been carried out to find both short- and long-term solutions to issues routinely faced by health and social care professionals, such as the management of waiting lists and bed capacity, clinical pathway redesign, workforce planning and scheduling, performance management, disease monitoring, and health care technology assessment. More recently, the need for more refined and inclusive approaches to modelling and simulation that embrace technical, organisational, clinical, social and experiential considerations has been recognised (www.cumberland-initiative.org).

The Institute of Mathematics and its Applications (IMA, www.ima.org.uk), the UK's learned and professional society for mathematics and its applications, has been organising the IMA International Conference on Quantitative Modelling in the Management of Health Care since 1995. The aim of the conference is to bring together health care managers, clinicians, management consultants, and mathematicians, operational researchers, statisticians, economists and computer scientists from across the world with a view to bridging the gap between the communities and to exploring recent developments and identifying fruitful avenues for further research.

The sixth instalment of the conference (IMA Health 2010) was held at Mary Ward House, London, UK between 29 and 31 March 2010. Chaired by Prof Thierry Chaussalet, professor at the University of Westminster it featured four keynote speakers, about 50 oral presentations organised in 14 parallel sessions and over a dozen poster presentations. The keynote speakers included (in order of presentation):

- Prof William Pierskalla, Professor Emeritus and former Dean of the UCLA Anderson School of Management (title of talk: Health care delivery faces many strategic 
and tactical problems but we are making progress in many areas);

- Prof Sir Bruce Keogh, consultant cardiovascular surgeon and NHS Medical Director (Patients, providers and p-values: any significance?);

- Dr David Worthington, senior lecturer with the Lancaster University Management School (Queue modelling and healthcare: chalk and cheese or fish and chips?);

- Kate Silvester, a clinical systems improvement specialist (The maths behind a hospital's heart failure).

Conference delegates came from a plethora of countries and continents, with researchers based in the USA, Canada and North America adding to the strong presence of academics and practitioners from the UK and other European countries. The conference was sponsored by the NHS Institute for Innovation and Improvement and MASHnet, the UK network for modelling and simulation in healthcare (www.mashnet.org.uk), and the software companies AIMMS and GUROBI.

\section{HCMS special issue}

There have been four previous Health Care Management Science special issues devoted to papers presented at IMA Health conferences [5-8]. This special issue contains nine papers that were among those submitted for consideration following the conference and underwent additional rigorous peer review. In line with previous conferences, the papers included in this issue tend to have a more practical focus whilst the more mathematical papers are currently being considered for publication by the IMA journal of Management Mathematics.

The nine papers of this special issue have been grouped into two broad categories. First, we have included four papers that report on modelling studies conducted at or relevant to hospital operations and clinical practice; in other words studies aimed at the micro level. The five remaining papers concern studies at the macro level, which are relevant to regional or national planners and policymakers.

In the micro level group, the first paper by Reddy and colleagues report on a study conducted in collaboration with clinicians from Papworth Hospital in Cambridge, UK to develop a risk stratification scheme for identifying those patients at higher risk of post-operative bleeding following cardiac surgery. Reynolds et al reports on the results of a detailed discrete-event simulation study of the hospital pharmacy outpatient dispensing systems at two large London hospitals. Bekker and Koeleman utilise analytical methods from queuing theory and optimisation to derive practical guidelines in support of the quota admission scheduling method. In a technical note, Gallivan and Utley provide a brief but useful analysis on estimating demand for beds to accommodate emergency referrals assuming that all patients have the same length of stay distribution and the number of daily emergency referrals is Poisson distributed.

In the macro level group, Jones and colleagues compare two simple arithmetic methods of determining the population catchment areas of hospitals with a more advanced modelling method that includes notions of travel time. Fiorentino et al describe an analytical model to help estimate future trends in cancer prevalence in the UK using estimates and trends in cancer incidence and survival. Min Hua and colleagues propose, evaluate and compare with more traditional techniques a procedure for automating casemix adjustment in the context of monitoring health outcomes. Gillespie et al demonstrates how phase-type models could be used to model the cost of treating stroke patients within a health care facility and to evaluate the likely benefits of increasing the usage of thrombolysisinducing drugs in the early treatment of such patients. Finally, Bowers uses simulation to explore and discuss issues related to the use of targets on the management of surgical waiting list lists.

\section{References}

1. Department of Health (2010) Equity and excellence: liberating the NHS. Department of Health, London

2. Delamothe T, Godlee F (2011) Dr Lansley's monster. BMJ 342: d408

3. Tomassini C, Glaser K, Wolf DA, Broese van Groenou MI, Grundy E (2004) Living arrangements among older people: an overview of trends in Europe and the USA. Popul Trends 24-34.

4. Bhutta ZA, Chopra M, Axelson H, Berman P, Boerma T, Bryce J et al (2010) Countdown to 2015 decade report (2000-10): taking stock of maternal, newborn, and child survival. Lancet 375:20322044

5. Baker RD (1998) Special issue. Health Care Manag Sci 1:1

6. Baker RD (2002) Special issue. Health Care Manag Sci 5:237

7. Baker RD (2005) Special issue. Health Care Manag Sci 8:187

8. Baker RD, Chaussalet TJ, Utley M (2008) Special issue. Health Care Manag Sci 11:87 